\title{
Nanofibre fabrication in a temperature and humidity controlled environment for improved fibre consistency
}

\author{
Oliver Hardick • Bob Stevens • Daniel G. Bracewell
}

Received: 9 November 2010/ Accepted: 19 January 2011/Published online: 2 February 2011

(C) Springer Science+Business Media, LLC 2011

\begin{abstract}
Fabricating nanofibres with reproducible characteristics is an important demand in the membrane industry in order to establish commercial viability. In this study, the effect of controlled atmospheric conditions on electrospun cellulose acetate (CA) nanofibres was evaluated for temperatures ranging $17.5-32.5{ }^{\circ} \mathrm{C}$ and relative humidity ranging $20-70 \%$. CA solution $(0.2 \mathrm{~g} / \mathrm{mL})$ in a solvent mixture of acetone/dimethylformamide/ethanol $(2: 2: 1)$ was electrospun into nonwoven fibre mesh with the fibre diameter ranging from $150 \mathrm{~nm}$ to $1 \mu \mathrm{m}$. The resulting nanofibres were analysed by differential scanning calorimetry, showing a correlation of reducing melt enthalpy with increasing atmospheric temperature. The opposite was seen with increasing atmospheric humidity, which conferred increasing melt enthalpy. Analysis of scanning electron microscopy images provided a correlation of reducing average fibre diameter with increasing atmospheric temperature and increasing fibre diameter with increasing atmospheric humidity. These results correlate with the melt enthalpy results, suggesting that finer CA nanofibres infer a lower melt enthalpy. Together these studies provide strong evidence that the controlled atmospheric conditions affect the fibre diameter of the resulting electrospun nanofibres. A salient observation in this study was that increased humidity reduced the effect of fibre
\end{abstract}

\section{O. Hardick · B. Stevens}

Micro and Nanotechnology Centre, Science and Technology

Facilities Council, Rutherford Appleton Laboratory,

Didcot OX11 0QX, United Kingdom

O. Hardick $(\square)$. D. G. Bracewell

The Advanced Centre for Biochemical Engineering, Department

of Biochemical Engineering, University College London,

Torrington Place, London WC1E 7JE, United Kingdom

e-mail: oliver.hardick@stfc.ac.uk beading yielding a more consistent and therefore better quality of fibre. This has apparent implications for the reproducibility of nanofibre production and offers a new method of controlling fibre morphology. This study has highlighted the requirement to control atmospheric conditions during the electrospinning process to fabricate reproducible fibre mats.

$\begin{array}{ll}\text { Abbreviations } \\ \text { DMF } & \text { Dimethylformamide } \\ \text { CA } & \text { Cellulose acetate } \\ \text { SEM } & \text { Scanning electron microscopy } \\ \text { DSC } & \text { Differential scanning calorimetry } \\ \text { RH } & \text { Relative humidity } \\ T_{\mathrm{g}} & \text { Glass transition temperature } \\ T_{\mathrm{m}} & \text { Melting temperature }\end{array}$

\section{Introduction}

The first significant report of electrospinning to produce polymer fibres came in 1934 when a patent by Formhals [1] was issued which described electrospinning as a process for forming textile fibres. To date, applications of nanofibres have included textiles, medical materials, filtration devices, bioengineering materials and even energy cells [2-5]. In the medical sector, nanofibres have been used to produce artificial organ components, implant material, tissue replacement and wound dressing and are the subject of much recent attention [6-8].

The electrospinning process uses an electrical charge to draw fibres from a polymer-solvent solution (Fig. 1). The basic laboratory setup consists of a spinneret (micro needle) connected to a high-voltage $(5-30 \mathrm{kV})$ power supply, 


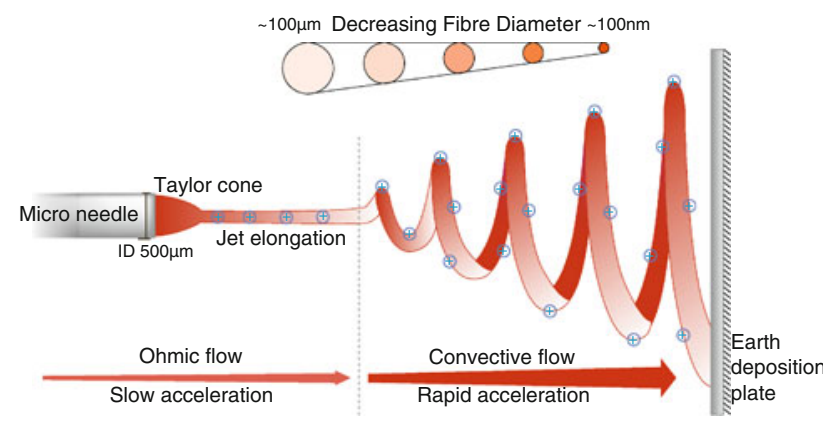

Fig. 1 Nanofibre formation by electrospinning (not to scale). When a sufficient electrical charge is applied the body of the polymer-solvent solution becomes charged. As the electrostatic forces overcome the surface tension, a Taylor cone is formed. A thin cylindrical jet emanates from the droplet surface extending towards the direction of the electric field. Elongation along this axis continues until electrical bending instability occurs. Here the mode of current flow changes from ohmic to convective as the charge migrates to the surface of the fibre. This causes the jet to quickly bend through $90^{\circ}$ leading into a series of loops under rapid acceleration. This 'whipping' process is responsible for nanometre-scale reduction in fibre diameter

a syringe pump and a grounded collector plate. The polymer solution is extruded from the needle tip at a constant rate by the syringe pump, forming a droplet. The voltage applied causes the droplet to stretch into a Taylor cone. If the molecular cohesion of the material is sufficiently high, stream breakup does not occur (if it does, droplets are electrosprayed) and a charged liquid jet is formed. The jet is then elongated by a whipping process caused by electrostatic repulsion initiated at small bends in the fibre stretching it to nanometre-scale before being deposited on the grounded collector. The solvent must evaporate for the polymer to solidify and form a fibre [9-11].

The application of nanofibres continues to grow through a multitude of industries where product reproducibility is expected or required by validation and regulation [12-15]. Indeed all products should be sold with relevant documentation stating the product specification. This requires rigorous quality assurance testing of which reproducibility will be a key part. Therefore, to assure nanofibre use is accessible and applicable for many markets, an ability to control the production must be established. This study is particularly relevant to membrane operations which are commonly limited by poor membrane pore size uniformity and axial and radial diffusion which results in poor system dispersion, yielding low utilisation of membrane capacity $[16,17]$. Previous studies have highlighted the importance of designing a membrane with regards to the proposed system and operating conditions, optimising the membrane pore size by balancing mass transfer against and fouling issues [18-20].

Numerous electrospinning parameters affect the resulting nanofibre characteristics. Owing to the difficulty of precisely controlling these various parameters, the reproducible production of nanofibres becomes problematical and an issue for development in industry, especially biotechnology and healthcare. These parameters can be split up into three subcategories:

- Polymer solution parameters which involve rheological and chemical properties of solutions.

- Processing conditions which include applied voltage, flowrate and spinneret and collector properties.

- Ambient parameters where atmospheric conditions interact with the system to affect fibre morphology.

Varying any of these parameters even by small amounts can have a large effect on the structure of fibres produced; this enables the formation of fibres with defined features such as fibre diameter, flat ribbon or cylindrical fibres, level of fibre surface porosity and bead formation. Depending on the intended application, these properties have the potential to be selected and specifically expressed. For example, thinner fibres may be preferred due to the larger surface area that they convey but often a small diameter presents a reduction in fibre strength.

In the current literature which covers nanofibre production, it has typically been the polymer solution parameters and processing conditions which have been investigated. However, to ensure a reproducible and optimised product, the effect of the electrospinning environment by controlling air temperature and humidity was investigated. The system chosen here is the electrospinning of cellulose acetate (CA) nonwoven nanofibre mats using three different temperatures and relative humidities (RHs) in a controlled environment cabinet to evaluate the effect on the resulting average nanofibre diameter by scanning electron microscopy (SEM) and the corresponding thermal properties of the nanofibres by differential scanning calorimetry (DSC). The polymer solution parameters and processing conditions remain fixed for the entire investigation.

\section{Experimental}

\section{Materials}

A solution of $\mathrm{CA}(\mathrm{Mr}=29,000 ; 40 \%$ acetyl groups; $0.20 \mathrm{~g} / \mathrm{mL})$ in acetone/dimethylformamide/ethanol (2:2:1) was electrospun to obtain CA nanofibre nonwoven membranes. All materials were bought from Sigma-Aldrich (Sigma-Aldrich Company Ltd. Dorset, UK) and used without further purification.

\section{Electrospinning process}

The process was carried out in a ClimateZone climate control cabinet (a1-safetech Luton, UK) which allows the 
process to be performed under controlled atmospheric conditions. The temperature and RH were selected and kept constant throughout each electrospinning event from a temperature range: $17-35{ }^{\circ} \mathrm{C}$ (resolution of $0.1{ }^{\circ} \mathrm{C}$ ), and a humidity range: $20-80 \% \mathrm{RH}$ (resolution of $1 \% \mathrm{RH}$ ). A 5-mL polymer solution was loaded into a sterile syringe and attach to a Harvard PHD 4400 syringe pump (Harvard Apparatus Ltd. Kent, UK), with a programmable flow rate range from 0.0001 up to $13.25 \mathrm{~L} / \mathrm{h}$, to deliver the polymer solution to a $0.5-\mathrm{mm}$ ID stainless steel micro needle. The pump is set at a flowrate of $800 \mu \mathrm{L} / \mathrm{h}$. The tip of the needle was placed $30 \mathrm{~cm}$ above the grounded collector plate. The collector plate used was a rectangular $(20 \times 26 \mathrm{~cm})$ aluminium foil covered earth steel plate. The process was run for $1 \mathrm{~h}$. These conditions were selected based on preliminary experiments and are known to yield solid dry nanofibres with diameters from 0.1 to $1 \mu \mathrm{m}$. Electrospinning samples for the defined parameters were repeated on three different days allowing for the comparison of fibre consistency.

\section{DSC}

Thermal properties of the fibres were evaluated by a Netzsch DSC 200 F3 Maia (NETZSCH-Gerätebau GmbH, Selb, Germany) at a rate of $10{ }^{\circ} \mathrm{C} / \mathrm{min}$, heating at $25-260{ }^{\circ} \mathrm{C}$ in a nitrogen atmosphere. Ten samples of nanofibres were measured consisting of one sample from each of the nine possible combinations of temperature and humidity conditions and one sample of CA powder. The melt enthalpy values were calculated by taking the integral of the melt temperature curve using the DSC software.

\section{SEM}

Complete drying of the fibres was allowed before characterisation by scanning electron microscopy. Nonwoven fibre samples were analysed from three SEM images each with 20 individual measurements of nanofibre diameters. The 60 measurement points per fibre sample were selected randomly and gave a good coverage of the SEM images. Data was collected using imaging software by selecting ' $x$ ' and ' $y$ ' coordinate points along the nanofibre edges using magnified images. This does provided opportunity for human error in conjunction with the error given by pixelated images at high magnification. This was repeated for three different cuttings from a single electrospun fibre mat fabricated under a single set of constant conditions to calculate the average nanofibre diameter and standard deviation. The total number of samples imaged by the SEM was 81 ( 27 samples with 3 cuttings each) which generated a data total of 1620 fibre diameter measurements. Fibres diameters measured above $1 \mu \mathrm{m}$ were excluded from the average fibre diameter determination as they appeared to originate from bead formation. The SEM used was a Hitachi TM-1000 Tabletop microscope (Hitachi High-Technologies Europe Gmbh).

\section{Results and discussion}

Figure 2 shows an array of nine combinations of controlled parameters for three controlled temperatures $(17.5,25.0$ and $\left.32.5{ }^{\circ} \mathrm{C}\right)$ and three controlled humidities $(20,50$ and $70 \% \mathrm{RH})$ to assess the optimal ambient conditions with the fewest experiments.

\section{Thermal properties}

DSC was used to measure the energy required to heat each of the nine nanofibre samples from 25 to $260^{\circ} \mathrm{C}$. Melt enthalpy values were determined by taking the integral of the melting temperature curve from the thermograms. Enthalpy data is particularly relevant to the study of nanofibres as it expresses information about the morphology of the fibres. Previous studies have described pre and post electrospinning treatments to alter the fibre's structure conferring different glass transition temperature $\left(T_{\mathrm{g}}\right)$ and melt temperature $\left(T_{\mathrm{m}}\right)$ enthalpy values [21-25]. Any changes in melt enthalpy values should be caused and interpreted by the changes in the degree of crystallinity and/or macromolecular orientation within the electrospun fibres.

Figure 3 shows that the melt enthalpy decreases with increasing temperature. At $20 \% \mathrm{RH}$, the melt enthalpy decreased from 8.96 to $4.47 \mathrm{~J} / \mathrm{g}$ from a process temperature of $17.5-32.5{ }^{\circ} \mathrm{C}$. This decrease of $50 \%$ is significant and suggests that with increasing temperature comes a less ordered molecular structure since the energy required to make the phase change is greatly reduced. In this study where polymer solution parameters and process conditions have been kept constant, the observed reduction in melt enthalpy values are likely to be caused by faster solvent evaporation at a higher temperature which leaves less time for fibre solidification. This means that polymer macromolecules have less time to arrange, resulting in a lower degree of crystallization and less molecular orientation. This effect is concurrent with a reduction in fibre diameter since faster solvent evaporation will result in fewer interconnected chain entanglements making the energy required to separate these polymer molecules less than that for a thicker fibre. Lee et al. [26] demonstrated a similar effect using DSC to show that nanofibres fabricated from higher molecular weight polyvinyl acetate solutions shifted the $T_{\mathrm{m}}$ from 224.7 to $232.7{ }^{\circ} \mathrm{C}$ due to the effectively increased crystalline structure. Figure 3 also shows a clear distinction 


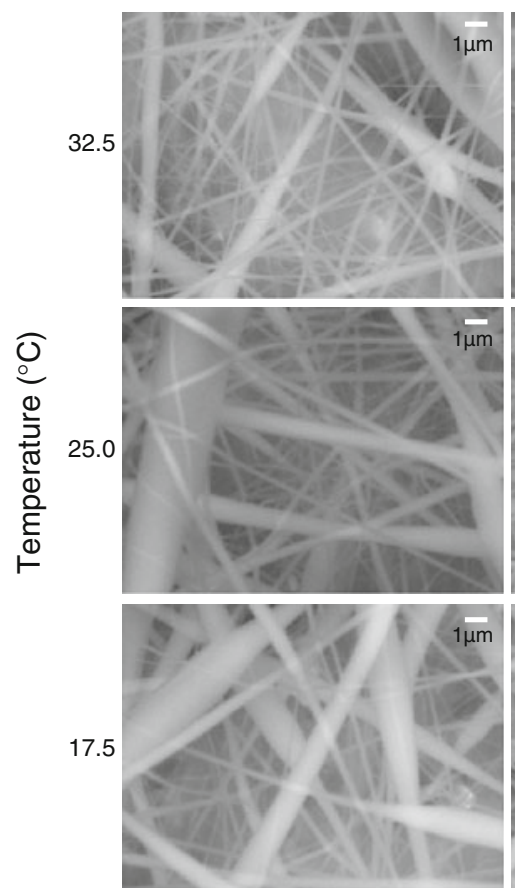

20

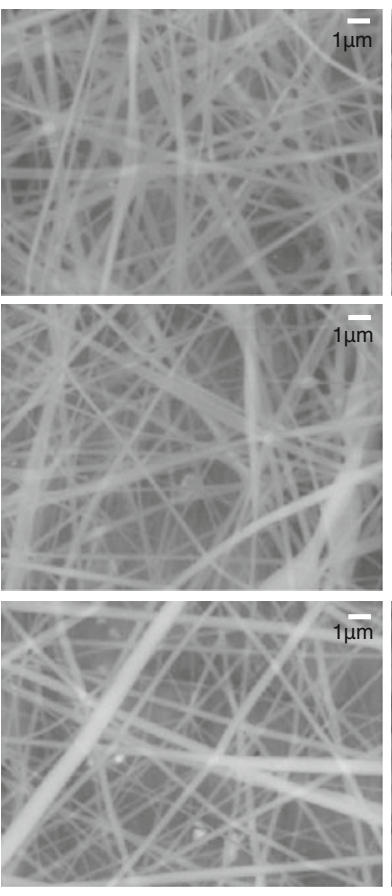

50

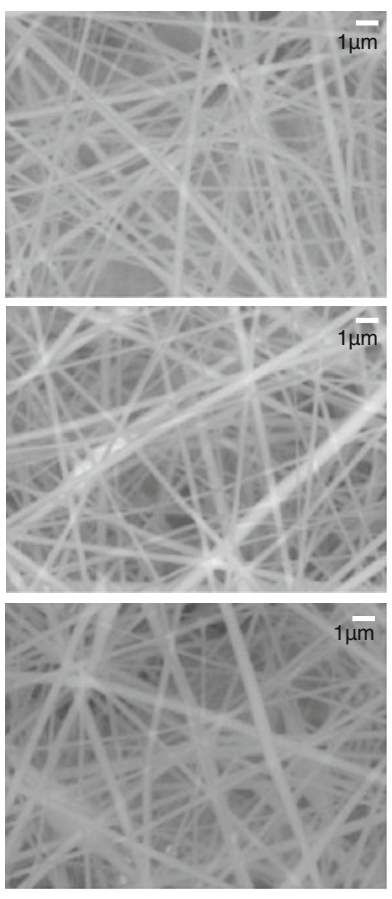

70

Relative Humidity (\%RH)

Fig. 2 Scanning electron microscopy images $(10,000 \times)$ of nanofibres produced under different controlled environment conditions. The white scale bar indicates $1 \mu \mathrm{m}$

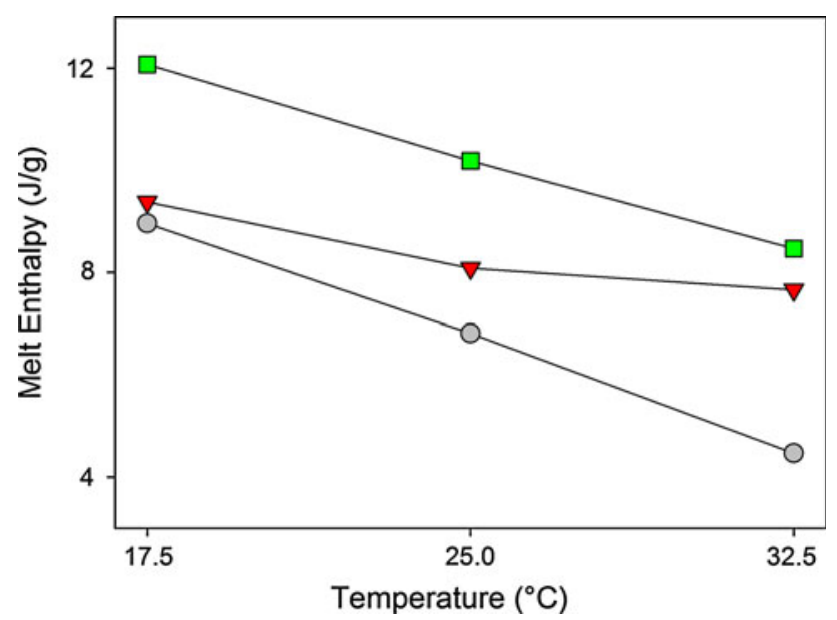

Fig. 3 Nine nanofibre samples prepared at different humidities and temperatures were analysed by differential scanning calorimetry to show the changes in melt enthalpy. Open circle $20 \%$, open inverted triangle $50 \%$ and open square $70 \%$ relative humidities

between the melt enthalpies of nanofibres fabricated at different controlled RHs, with the largest value being $12.07 \mathrm{~J} / \mathrm{g}$ for the nanofibres produced under the atmospheric conditions $17.5^{\circ} \mathrm{C}$ and $70 \% \mathrm{RH}$. Using $17.5^{\circ} \mathrm{C}$ as a constant variable, the melt enthalpy decreased from 12.07 to $8.96 \mathrm{~J} / \mathrm{g}$ for process humidities of 70 and $20 \%$, respectively.
The $T_{\mathrm{g}}$ was not obvious but the thermograms showed a small feature before the main melting peak at around $194{ }^{\circ} \mathrm{C}$ which is likely to correspond to bond breaking and irreversible plastic deformation occurrences at this point although this observation could have also been cause by the melting of less stable crystalline structure.

The powder form of CA was also investigated using DSC and yielded smaller peaks at 230 and $242{ }^{\circ} \mathrm{C}$. The melt enthalpy was not measurable here suggesting that the nanofibre structures confer a higher degree of order than the powder form. Zong et al. [27] used DSC to show that polylactic acid polymer had a crystallinity degree of $36 \%$ whereas polylactic acid nanofibres exhibited a much lower value. XRD results supported that although the polymer chains were non-crystalline in nanofibre form, they are highly orientated. This suggests that nanofibres do confer a high degree of order of polymer chains though their crystallinity is not high.

Fibre diameter and surface characteristics

The distribution of the data displayed in Fig. 4 is typical throughout. The data does not fit a Gaussian function; however, normal means were calculated to determine average fibre diameters which could then be plotted. The non-normal distribution observed could be an artefact from various factors such as the beading effect in this polymer system, the human aspect of collecting the data or the 


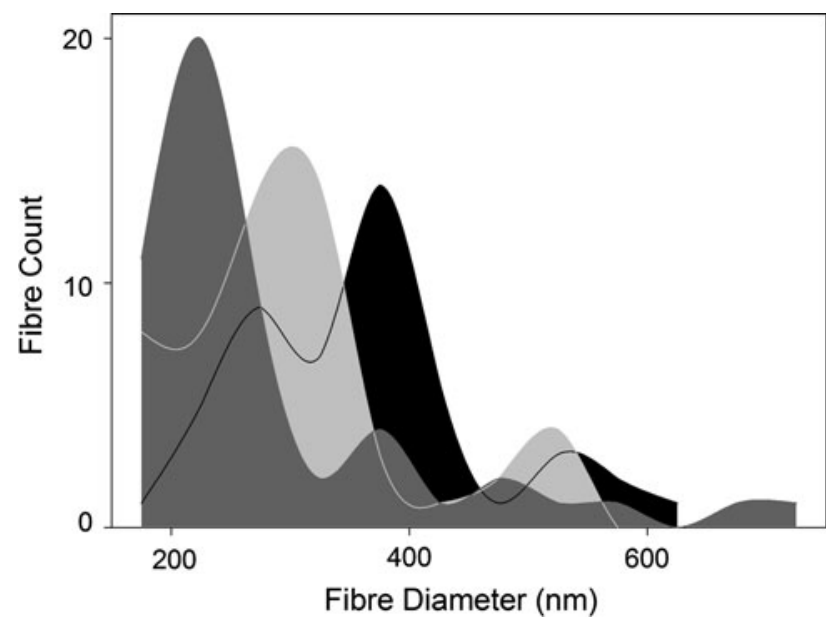

Fig. 4 Distributions of fibre diameters produced at $20 \%$ relative humidity for: black $17.5^{\circ} \mathrm{C}$, light grey $25.0{ }^{\circ} \mathrm{C}$, dark grey $32.5^{\circ} \mathrm{C}$ taken from 20 fibre diameter measurements from each sample. This shows that fibre diameter increases with increasing temperature

image resolution as described in the SEM section. The standard deviation error calculated is based on a normal distribution and is used is subsequent graph analyses.

The average fibre diameter for each sample was determined by taking an average of 60 measurements from nine SEM images for each of the controlled conditions. This was performed three times on three separate days. The change in average fibre diameter for the variable ranges was larger than the values reported by Mit-Uppatham et al. [28], which is not surprising because they employed a different polymer solvent system of polyamide- 6 in formic acid. Figure 5 shows that the fibre diameter decreases with increasing temperature. Using the $20 \% \mathrm{RH}$ as a constant variable the fibre diameter decreased from 360 to $284 \mathrm{~nm}$ for process temperatures 17.5 and $32.5{ }^{\circ} \mathrm{C}$, respectively. The rate of change in fibre diameter caused by the temperature change was not independent of humidity as shown by the percentage increase in fibre diameter of 31.2 and $11.0 \%$ for humidity conditions 20 and $70 \% \mathrm{RH}$, respectively. The average of the entire data showed an increase in fibre diameter of $1.29 \%$ per $1{ }^{\circ} \mathrm{C}$.

At an increased temperature the viscosity of the polymer-solvent solution is reduced. The lower viscosity allows the columbic forces to increase stretching, giving finer fibres. Mit-Uppatham et al. [28] demonstrated that an increase in temperature caused the decrease of solution viscosity, surface tension conductivity and the resulting polyamide- 6 fibre diameter. Increasing temperature also increases evaporation rate, this in conjunction with greater solubility allows for more even stretching and the deposition of more uniform fibres. This was observed by Demir et al. [29] in their study of parameters affecting the electrospinning of polyurethane fibres.

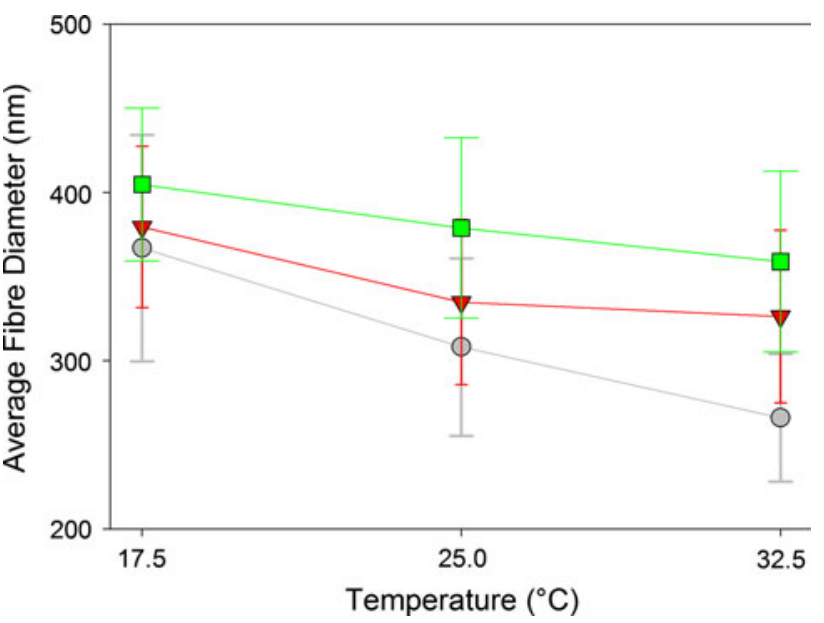

Fig. 5 Average fibre diameters versus process temperatures for open circle $20 \%$, open inverted triangle $50 \%$ and open square $70 \%$ relative humidities. Error bars are \pm 1 standard deviation of the sample population

Figure 6 indicates that the fibre diameter increases with increasing humidity. Using the $25{ }^{\circ} \mathrm{C}$ samples as a constant variable, the average fibre diameter increased from 300 to $352 \mathrm{~nm}$ for process humidities 20 and $70 \%$, respectively. Here the average change in fibre diameter was $0.30 \%$ per $1 \% \mathrm{RH}$. As mentioned previously, the rate of change in fibre diameter caused by temperature change was not independent of process humidity. This is clearly visible in Fig. 6 and is due to the wider range of fibres observed at lower humidities caused by the beading effect.

An increase in relative atmospheric humidity results in a decrease in evaporation rate favouring finer fibre formation. The increased water in the atmosphere would also suggest a slowing of the solidification process resulting in a longer flight time and therefore finer fibre formation; however, the effects observed here suggest the opposite occurrences. This case is perhaps specific to CA which upon addition of water results in fast polymer precipitation; therefore, as the humidity increases, it can be speculated that the increased water absorption causes the jet to precipitate out of solvent more quickly thereby reducing the flight time and elongation of the polymer fibre, resulting in thicker fibre. Most likely the more dominant effect is the increase in charge dissipation at higher $\mathrm{RH}$ due to the additional water present in the atmosphere resulting in lower charge repulsion by the polymer during the whipping stage, favouring the formation of thicker fibres. If the relative humidity is too high the deposition of wet fibres can occur causing them to fuse together before drying. These occurrences, explained by Baumgarten [30], affect the fibre diameter but perhaps the more interesting effect from changes in humidity is that to the fibre surface roughness or porosity. The correlation observed could also be due to a 


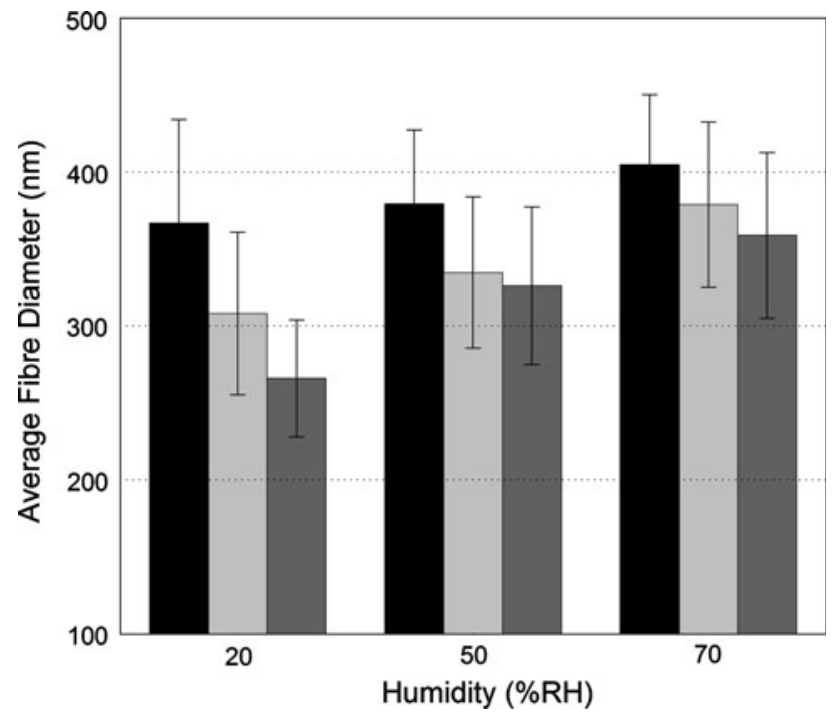

Fig. 6 Average fibre diameters versus process humidity: black $17.5^{\circ} \mathrm{C}$, light grey $25.0^{\circ} \mathrm{C}$, dark grey $32.5^{\circ} \mathrm{C}$. Error bars are \pm 1 standard deviation of the sample population

less dense fibre being formed at a higher humidity. At sufficient atmospheric humidity, water condenses on the surface of the fibre during electrospinning. If a volatile solvent is being used, pores form when both the water and solvent evaporate. Pore size increases with increasing humidity until they coalesce to form large non-uniform pores. Casper et al. [31] showed that electrospinning polystyrene at a $\mathrm{RH}$ of $31-38 \%$ was enough to see the formation of fibre surface pores. They also showed that surface pores of size increased with $\mathrm{RH}$, seeing average pore sizes of $85 \mathrm{~nm}$ at $31-38 \% \mathrm{RH}$ and $135 \mathrm{~nm}$ at $66-72 \%$ RH. Bognitzki et al. [32] reported that using a solvent with a lower vapour pressure reduced the formation of pores on polylactic acid porous nanofibres. Megelski et al. [33] observed the same effect of reduced pore formation with decreasing vapour pressure using the example of polystyrene and varying ratio THF/DMF solvent mixtures. As the ratio of the less volatile DMF increases, therefore reducing the vapour pressure, surface roughness or microtexture decreased, at $100 \%$ DMF, smooth fibres were formed. Many of the lower RH samples contained a beaded fibre system and thus fibre diameters over $1 \mu \mathrm{m}$ were excluded from the data. It also yielded a large error due to some partially formed beads represented as thicker sections of fibre.

Figure 7 shows that as the fibre diameter decreased so did the melt enthalpy, which was expressed by a broad low endothermic peak. The largest fibres $\left(17.5^{\circ} \mathrm{C}, 70 \% \mathrm{RH}\right.$ : $385 \mathrm{~nm}$ ) yielded the largest melt enthalpy of $12.07 \mathrm{~J} / \mathrm{g}$ compared with the $4.47 \mathrm{~J} / \mathrm{g}$ yielded by the finest fibres $\left(32.5{ }^{\circ} \mathrm{C}, 20 \% \mathrm{RH}: 276 \mathrm{~nm}\right)$. Thus, a decreased crystallinity and a less ordered molecular structure occur with

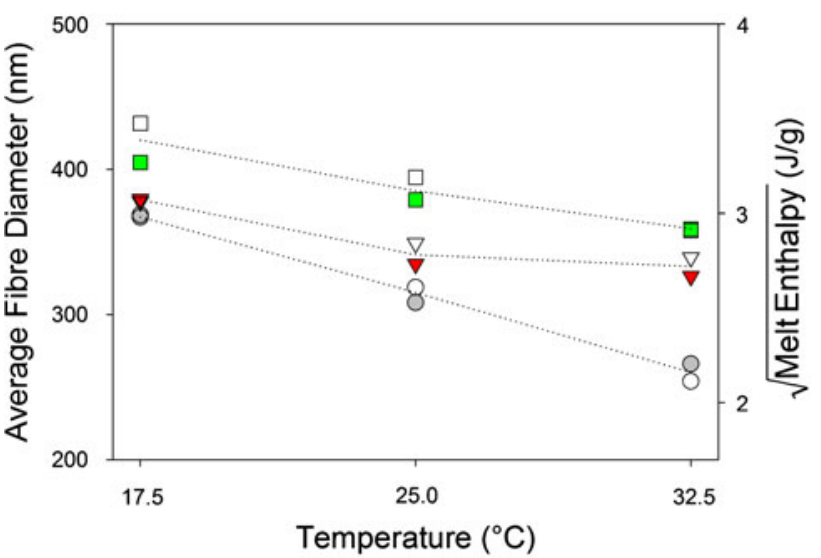

Fig. 7 Results of average fibre diameters (filled symbols) and melt enthalpies (open symbols) versus process temperature of fibres fabricated under different controlled conditions for open circle $20 \%$, open inverted triangle $50 \%$ and open square $70 \%$ relative humidities

decreasing fibre diameter. This clearly suggests that controlled atmospheric conditions affect fibre diameter.

\section{Consistency and reproducibility}

Reproducible fabrication of nanofibres is essential for their mass production for commercial purposes. The nine controlled condition parameters repeated on three separate days were assessed. Although there are bead formation issues that occur when electrospinning $\mathrm{CA}$, the consistency of average fibre diameter from the samples electrospun on different days can be seen in Fig. 8. The greatest difference in average fibre diameter among samples electrospun under the same conditions but on different days was $27.3 \mathrm{~nm}$ which corresponded to a difference of $7.5 \%$. The average difference, however, was $4.3 \%$ which is perfectly respectable considering the variety of fibre characteristics. The distribution of data over the three separate days was consistent, supporting that this polymer-solvent system has sufficient reproducibility.

\section{Fibre quality}

Figure 9 shows an SEM image matrix, suggesting that the polymer-solvent system was in a state near to or actually producing a beaded fibre structure. Figure 10 summarises the extent of beading as determined by analysing 27 SEM images from the nine controlled conditions over the 3 days. The most uniform fibres, and the ones with the least amount of beading, were those electrospun at high humidity. High $\mathrm{RH}$ appeared to be the dominant process variable in the goal for homogeneity though atmospheric temperature did have an effect (Fig. 9). 

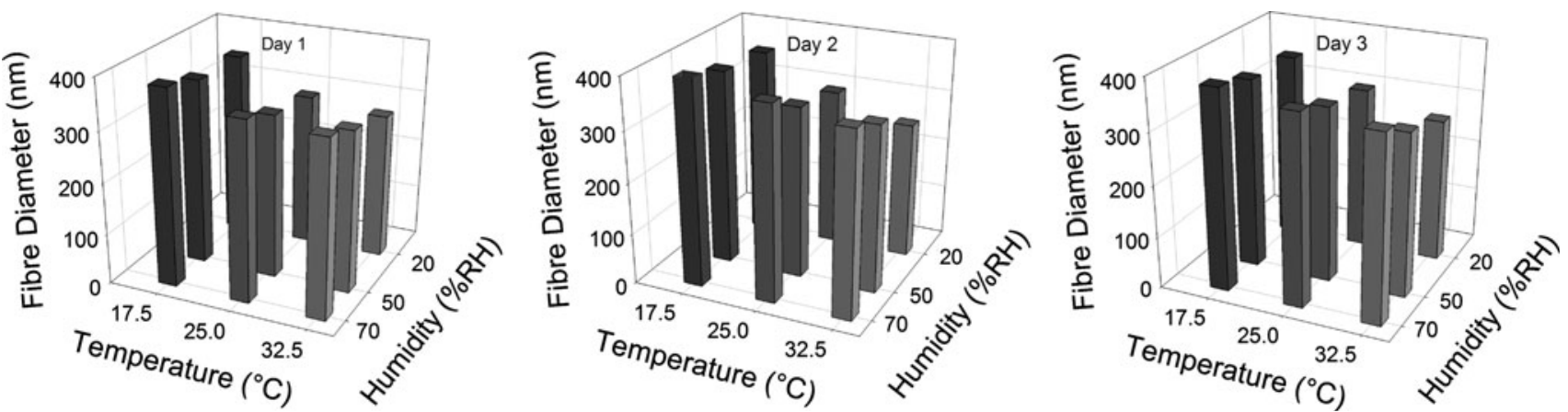

Fig. 8 Average fibre diameters for the controlled environment conditions repeated over three separate days suggest that nanofibres can be fabricated reproducibly using the polymer-solvent system and apparatus setup described in this study

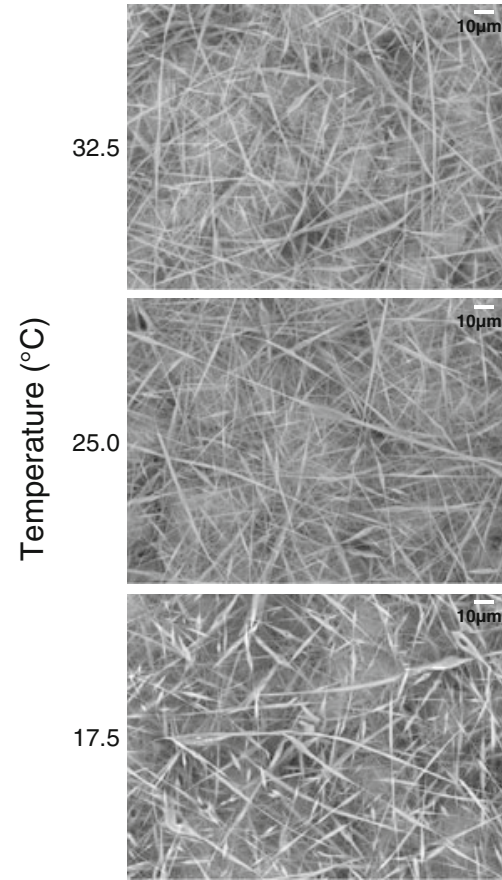

20
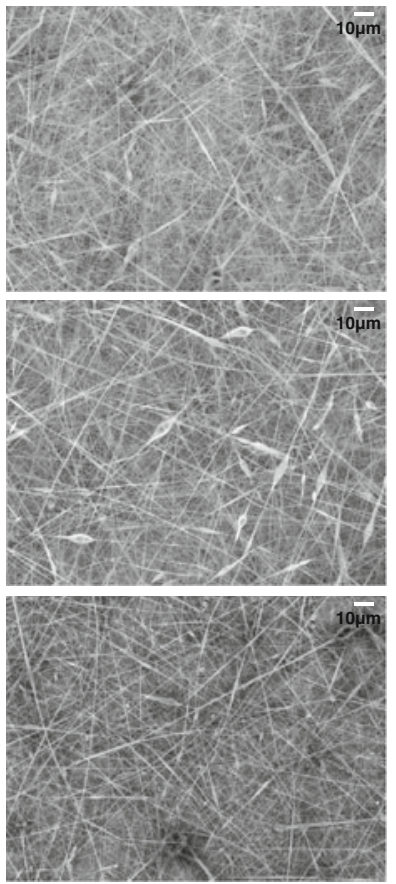

50
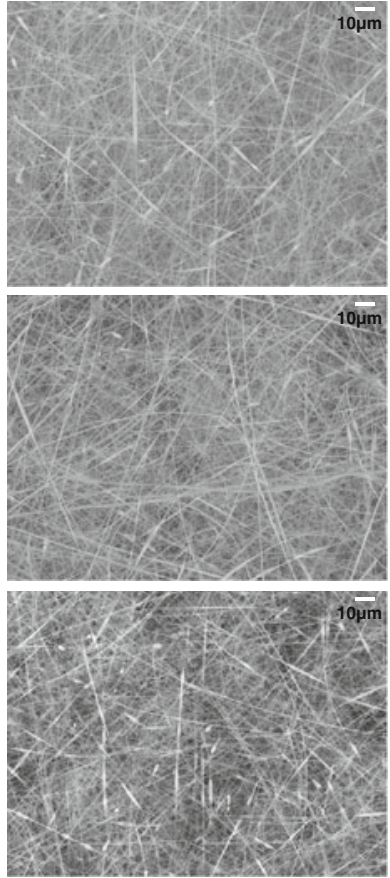

70

Relative Humidity $(\% \mathrm{RH})$

Fig. 9 Scanning electron microscopy images $(1,000 \times)$ for fibres electrospun under different controlled environments showing the extent of beading and fibre consistency. White scale bar indicates $10 \mu \mathrm{m}$

The effect of increased humidity, and to a lesser extent temperature, on the formation of bead could be due to the reduced evaporation rate, which allows greater stability of the chain entanglements due to increased flight time. The reduced beading effect improves homogeneity of the fibres, which can be seen as an advantage in the effort of fabricating reproducible fibres. The change in beading effect with change in temperature could be caused by the reduced viscosity of the polymer solution allowing for a more even stretching due to the more dominant effect of the columbic forces [29]. However, this effect is not as noticeable due to the converse effect of the increased surface tension that occurs at increased temperatures. Surface tension can be a common cause of bead formation in electrospinning. Where there is a high concentration of free solvent molecules there is a tendency for them to congregate, adopting a spherical shape and giving rise to the bead formation. The use of low surface tension solvents such as ethanol encourages smooth fibre formation as does adding surfactants to the solution to reduce surface tension [34].

The increased beading effect displayed with decreasing humidity could also be due to a polymer-solvent solution droplet drying at the tip of the micro-needle. With reduced humidity, the evaporation of the volatile solvent mixture 


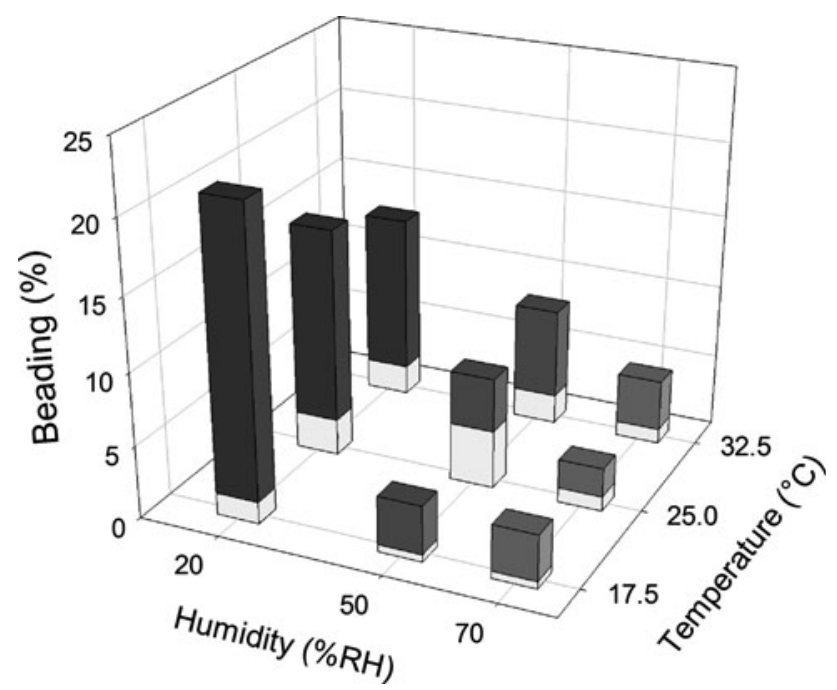

Fig. 10 Average amount of beading from the different controlled environments. Fibre diameters above $1 \mu \mathrm{m}$ were counted as a single bead. Bead counts were done using $2500 \times$ SEM images with the averages from each day plotted. Beading is expressed in percentage terms: number of beaded fibres versus total number of fibres in the SEM image. The error is shown by the light grey block section at the bottom of each bar. It has been calculated as 1 standard deviation of the sample population

occurs at such a rate that the polymer begins to dry before it is spun out into fibre jets. This causes pulses of fibre jets leading to the formation of polymer beads along the fibres formed. Zong et al. [27] noted a similar effect due to using a polymer solution at a very high concentration. Another effect formed by a mechanism relating to fast solvent evaporation is the formation of ribbon-like or flattened fibres. Should the polymer-solvent system be at such a state where a thin polymer skin forms on the liquid jet surface as a result of hyper solvent volatility the liquid core can succumb to the atmospheric pressure allowing the fibres to collapse in on them at the same time as complete solvent evaporation resulting in flattened fibre formation [35]. Koski et al. [36] observed that higher molecular weight polymer-solvent systems of poly(vinyl alcohol) in water produced ribbon-like fibres. Luo et al. [37] demonstrated the importance of the solvent choice and developed a spinnability-solubility map to enable the systematic selection of solvents creating electrospinnable binary solvent systems for polymethylsilsesquioxane.

\section{Conclusions}

Cellulose acetate nanofibres were electrospun under nine different ambient conditions over three separate days and the effects of process temperature and process humidity on the resulting fibre morphology were investigated. The SEM results indicated the expected correlation of decreasing average fibre diameter with increasing process temperature. A correlation was also observed whereby the fibre diameter increased with increasing humidity. The fibre diameters were also found to be consistent over the 3 days, suggesting a high reproducibility. In addition, the RH levels during the electrospinning process appeared to be the dominant factor in determining the level of bead formation. This is most likely due to the change in evaporation rate which determines the stability of the chain entanglements due to flight time. This notable observation has given new possibility for the controlling of beading nanofibre systems and has highlighted the importance of controlling atmospheric conditions during the electrospinning process.

The atmospheric conditions most suitable for nanofibre production in this study are $25.0{ }^{\circ} \mathrm{C}$ and $50 \% \mathrm{RH}$, which gives the highest level of fibre diameter uniformity, the lowest level of beading and maintains a low fibre diameter for increased surface area and increased pore size homogeneity. The DSC results support the SEM study and show the critical parameter to be atmospheric humidity because of the effect to homogeneity caused by fibre beading. The effect of the atmospheric humidity on the melt enthalpy was comparable with changes in the polymer solution parameters or other processing conditions. Therefore, the ambient parameters require an equal amount of consideration in the reproducible production of nanofibres by electrospinning. This study is particularly relevant to the membrane industry where beading would result in a poor quality membrane structure.

Acknowledgements Support for O.H. as part of the IMRC for Bioprocessing in the Advanced Centre for Biochemical Engineering by the Engineering and Physical Sciences Research Council (EPSRC) under the Innovative Manufacturing Research initiative is gratefully acknowledged. Support from Dr. Rob McKean at the Micro and Nanotechnology Centre, Science and Technology Facilities Council was greatly appreciated. Also, the authors thank Stewart R Dods and Dr. Anke Lohmann for their assistance during manuscript preparation.

\section{References}

1. Formhals A (1934) US Patent No. 1975504

2. Barnes CP, Sell SA, Boland ED, Simpson DG, Bowlin GL (2007) Adv Drug Deliv Rev 59:1413

3. Kumbar SG, Nukavarapu SP, James R, Nair LS, Laurencin CT (2008) Biomaterials 29:4100

4. Grafe TH, Graham KM (eds) (2003) Nanofiber Webs from Electrospinning. Donaldson Company Inc., Minneapolis. http:// www.donaldson.com/en/filtermedia/support/datalibrary/003321.pdf Accessed 01 Dec 2009

5. Kim JR, Choi SW, Jo SM, Lee WS, Kim BC (2004) Electrochim Acta 50:69

6. Zeng J, Xu X, Chen X, Liang Q, Bian X, Yang L, Jing X (2003) J Control Release 92:227

7. Verreck G, Chun I, Rosenblatt J, Peeters J, Van Dijck A, Mensch J, Noppe M, Brewster ME (2003) J Control Release 92:349 
8. Kim K, Luu YK, Chang C, Fang D, Hsiao BS, Chu B, Hadjiargyrou M (2004) J Control Release 98:47

9. Li D, Xia X (2004) Adv Mater 16:1151

10. Reneker DH, Fong H (eds) (2006) Polymeric nanofibers. American Chemical Society, Washington, DC

11. Ramakrishna S, Fujihara K, Teo W-E, Lim T-C, Ma Z (2005) An introduction to electrospinning and nanofibers. World Scientific Publishing Co. Ptd. Ltd, Singapore

12. Garcia JJ, Gresh RE, Gareis MB, Haney RA (1999) In: Proceedings of the 8th US Mine Ventilation Symposium, University of Missouri at Rolla, June 1999

13. Ramakrishna S, Fujihara K, Teo W, Yong T, Ma Z, Ramaseshan R (2006) Mater Today 9:40

14. Webster T, Waid MC, McKenzie JL, Price RL, Ejiofor JU (2004) Nanotechnology 15:48

15. Rathore AS, Sofer G (2005) Process validation in manufacturing of biopharmaceuticals. Informa Healthcare, London

16. Zeng X, Ruckestein E (1996) Ind Eng Chem Res 35:4169

17. Tejeda A, Ortega J, Magana I, Guzman R (1999) J Chromatogr A 830:293

18. Weissenborn M, Hutter B, Singh M, Beeskow TC, Anspach FB (1997) Biotechnol Appl Biochem 25:159

19. Tennikov MB, Gazdina NV, Tennikova TB, Svec F (1988) J Chromatogr A 798:55

20. Sarfert FT, Etzel MR (1997) J Chromatogr A 764:3

21. Kumar S, Rath T, Mahaling RN, Das CK (2007) Composites A 38:304
22. Suzuki A, Aoki K (2008) Eur Polym J 44:2499

23. Zhmayeva E, Choa D, Joo YL (2010) Polymer 51:274

24. Sandler JKW, Pegel S, Cadek M, Gojny F, van Es M, Lohmar J, Blau WJ, Schulte K, Windle AH, Shaffer MSP (2004) Polymer 45:2001

25. Inai R, Kotaki M, Ramakrishna S (2005) Nanotechnology 16:208

26. Lee JS, Choi KH, Ghim HD, Kim SS, Chun DH, Kim HY, Lyoo WS (2004) J Appl Polym Sci 93:1638

27. Zong X, Kim K, Fang D, Ran S, Hsiao BS, Chu B (2002) Polymer 43:4403

28. Mit-Uppatham C, Nithitanakul M, Supaphol P (2004) Macromol Chem Phys 205:2327

29. Demir MM, Yilgor I, Yilgor E, Erman B (2002) Polymer 43:3303

30. Baumgarten P (1971) J Colloid Interface Sci 36:71

31. Casper CL, Stephens JS, Tassi NG, Chase DB, Rabolt JF (2004) Macromolecules 37:573

32. Bognitzki M, Czado W, Frese T, Schaper A, Hellwig M, Steinhart M, Greiner A, Wendorff JH (2001) Adv Mater 13:70

33. Megelski S, Stephens JS, Chase DB, Rabolt FJ (2002) Macromolecules 35:8456

34. Fong H, Chun I, Reneker DH (1999) Polymer 40:4585

35. Koombhongse S, Liu W, Reneker DH (2001) J Polym Sci B 39:2598

36. Koski A, Yim K, Shivkumar S (2004) Mater Lett 58:493

37. Luo CJ, Nangrejo M, Edirisinghe M (2010) Polymer 51:1654 